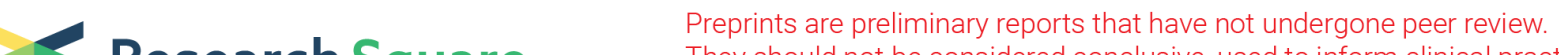 Research Square
They should not be considided conclusive, used to inform clinical practice,
or referenced by the media as validated information.
}

\section{Evaluation of Oxidative Stress, Inflammation, Apoptosis, Oxidative DNA Damage and Metalloproteinases in the Lungs of Rats Treated With Cadmium and Carvacrol}

\section{Kerim Yesildag}

Konya Numune Hospital: Konya Numune Hastanesi

Cihan Gur

Ataturk University: Ataturk Universitesi

Mustafa lleriturk

Ataturk University: Ataturk Universitesi

Fatih Mehmet Kandemir ( $\nabla$ fmehmet.kandemir@atauni.edu.tr)

Ataturk University: Ataturk Universitesi

\section{Research Article}

Keywords: Apoptosis, cadmium, carvacrol, lung toxicity, inflammation, oxidative stress

Posted Date: September 24th, 2021

DOl: https://doi.org/10.21203/rs.3.rs-918509/v1

License: (c) (1) This work is licensed under a Creative Commons Attribution 4.0 International License. Read Full License

Version of Record: A version of this preprint was published at Molecular Biology Reports on November 18th, 2021. See the published version at https://doi.org/10.1007/s11033-021-06948-z. 


\section{Abstract}

Background: The potential protective properties of carvacrol (CRV), which possesses various biological and pharmacological properties, against lung toxicity caused by cadmium (Cd), a major environmental pollutant, were investigated in the present study.

Methods and Results: In the study, rats were given 25 or $50 \mathrm{mg} / \mathrm{kg}$ CRV orally 30 minutes after administrating $25 \mathrm{mg} / \mathrm{kg}$ cadmium chloride for seven days. Subsequently, the levels of 8-OHdG, MMP-2, and MMP-9, as well as markers of oxidative stress, inflammation, and apoptosis, were analyzed in the lung tissue of the animals. The results revealed that CRV exhibited antioxidant characteristics and raised SOD, CAT, GPx, and CAT levels and decreased the MDA levels induced by Cd. It also suppressed proinflammatory cytokines by lowering the levels of CRV NF-kB and p38 MAPK, thus exerting an antiinflammatory effect against Cd. It was found that the levels of Bax, Caspase-3, and cytochrome $\mathrm{C}$ increased by $\mathrm{Cd}$ were decreased by the application of CRV. CRV also showed an anti-apoptotic effect by increasing Bcl-2 levels. The levels of 8-OHdG, MMP2, and MMP9, which increased with Cd administration, were observed to reduce after treatment with CRV.

Conclusions: The results show that CRV has protective properties against Cd-induced lung toxicity.

\section{Introduction}

Toxic metals are among the leading causes of environmental pollution, and their recognition is increasing day by day in terms of contributing to the pathophysiology of various diseases [1]. Among these toxic agents, cadmium (Cd) is one of the best known. $\mathrm{Cd}$ is not only one of the components of cigarette smoke but also widely used in battery, electroplating, pigment, plastic, and fertilizer industries [2, 3]. Humans are highly exposed to this highly toxic compound along with contaminated air, food, and water [4]. Because this metal can cause serious health problems by bioaccumulation in the human body, it will inevitably become a topic of international interest [5]. There is growing evidence that Cd damages the liver, kidneys, respiratory system, and nervous system [2,3]. For this reason, it has been added to the list of chemicals classified as globally hazardous by the International Register of Potentially Toxic Chemicals of the United Nations Environment Program [3].

Although the mechanism of $\mathrm{Cd}$ toxicity is not fully understood, recent studies indicate that oxidative stress plays a significant role in Cd toxicity [4]. Cd binding to glutathione and sulfhydryl groups of proteins leads to increased reactive oxygen species (ROS) and the inactivation of proteins. Elevated ROS has also been reported to cause DNA damage and activate pathways that cause cell apoptosis $[5,6]$. For this reason, it is believed that antioxidant compounds may be an effective treatment for cadmium toxicity, and interest in the use of naturally occurring phytochemicals is increasing day by day $[5,7,8]$.

Carvacrol (CRV) (5-isopropyl-2-methylphenol) is a phenolic monoterpene component of essential oils found in various Lamiaceae plants $[9,10]$. Previous in vitro and in vivo studies attributed antiinflammatory, antioxidant, antispasmodic, immunomodulatory, anticancer, and chemoprotective effects 
to this compound $[9,11,12]$. It has been reported that CRV not only increases the levels of endogenous antioxidants but also protects against inflammation, which is the underlying mechanism of many diseases, by regulating the expression of genes that play an essential role in inflammation [9].

The present study investigated the potential protective effect of CRV against pulmonary toxicity caused by $\mathrm{Cd}$. To uncover this, markers of oxidative stress, inflammation, apoptosis, and oxidative DNA damage were analyzed, as well as the activities of MMP-2 and MMP-9 in lung tissue.

\section{Materials And Methods}

\section{Animals used for the study and ethics committee approval}

The study included 35 male Sprague Dawley rats weighing 250-280 g and aged 10-12 weeks. Animals were provided by Atatürk University Experimental Research and Application Center (Erzurum, Turkey). After being randomly assigned into five groups in plastic cages, the rats were housed in an environment with $24 \pm 1 \circ \mathrm{C}, 45 \pm 5 \%$ humidity, and a 12 -hour light/dark cycle. Animals were fed standard rodent chow and water ad libitum. Before the experiment, the animals were acclimated to the environment for one week. Approval was obtained for the study from Atatürk University Animal Experiments Ethics Committee (Approval No. 2018/12/217).

\section{Experimental groups}

Each experimental group consisted of 7 animals. Doses of CRV and Cd were determined with reference to previous studies by Barnwal et al. (2018)[13] and Kim et al. (2018) [14], respectively. Experimental groups are given below.

1. Control group: Animals were orally given physiological saline for seven days and 30 minutes later were orally administered corn oil.

2. CRV group: Animals were orally administered $50 \mathrm{mg} / \mathrm{kg}$ CRV (98\% purity, Sigma-Aldrich chemicals, St. Louis, MO, USA) for seven days.

3. Cd group: Animals were orally administered $25 \mathrm{mg} / \mathrm{kg}$ cadmium chloride $\left(\mathrm{CdCl}_{2} ; 99.99 \%\right.$ purity, SigmaAldrich chemicals, St. Louis, MO, USA) for seven days.

4. Cd+CRV 25 group: Animals were given $25 \mathrm{mg} / \mathrm{kg} \mathrm{CdCl} 2$ orally for seven days and $25 \mathrm{mg} / \mathrm{kg}$ CRV orally 30 min later.

5. Cd+CRV 50 group: Animals were given $25 \mathrm{mg} / \mathrm{kg} \mathrm{CdCl} 2$ orally for seven days and $50 \mathrm{mg} / \mathrm{kg} \mathrm{CRV}$ orally 30 min later.

On day 8 of the study ( 24 hours after the last CRV administration), the animals were decapitated and their lung tissue removed after mild anesthesia with sevoflurane. Subsequently, lung tissue was used for 
biochemical, Real-Time PCR, and Western blot analyses.

\section{Preparation of tissue homogenates}

Rat lung tissue was first frozen with liquid nitrogen and then pulverized with a homogenizer (Tissue Lyser II, Qiagen, Netherlands). In the second phase, the tissues were diluted with $1.15 \%$ potassium chloride at a ratio of 1:10 (w/v) and then homogenized using the same homogenizer. Homogenates were centrifuged at $3500 \mathrm{rpm}$ for 15 minutes at $+4^{\circ} \mathrm{C}$ to analyze malondialdehyde (MDA), superoxide dismutase (SOD), and catalase (CAT). For glutathione (GSH) and glutathione peroxidase (GPx) analyses, it was centrifuged at $10000 \mathrm{rpm}$ for $20 \mathrm{~min}$ at $+4^{\circ} \mathrm{C}$.

\section{Analysis of oxidant and antioxidant markers in lung tissue}

MDA levels as oxidation markers in lung tissue were analyzed according to the Placer et al.

(1966) [15] method. The antioxidant markers SOD, CAT, and GPx activity and GSH levels were analyzed using the methods Sun et al. (1988)[16], Aebi (1984)[17], Lawrence and Burk (1976)[18] and Sedlak and Lindsay (1968)[19] respectively. Total protein levels of lung tissue used to calculate enzymatic antioxidant content were determined according to the method of Lowry et al. (1951)[20].

\section{Analysis of inflammatory markers in lung tissue by ELISA method}

Powdered tissue was diluted with phosphate-buffered saline (PBS) at a ratio of 1:20 (w/v) and homogenized with a homogenizer to analyze inflammatory markers in lung tissue by ELISA method. The homogenates obtained were centrifuged at $3500 \mathrm{rpm}$ for 15 minutes at $4{ }^{\circ} \mathrm{C}$. The levels of mitogenactivated protein kinase 14 (p38a MAPK), nuclear factor kappa B (NF-kB), B-cell lymphoma-3 (Bcl-3), inducible nitric oxide synthase (iNOS), cyclooxygenase-2 (COX -2), and prostaglandin E2 (PGE2) in the supernatant separated after centrifugation were analyzed according to the manufacturer's instructions (YL Biont, Shanghai, China).

\section{Analysis of 8-OHdG and MPO in lung tissue by ELISA method}

Levels of 8-hydroxy-2'-deoxyguanosine (8-OHdG) and myeloperoxidase (MPO) in lung tissue were determined using commercial ELISA kits from YL Biont (Shanghai, China). The analyses were carried out in strict accordance with the manufacturer's instructions.

\section{Analysis of apoptotic markers in lung tissue by ELISA method}

The levels of the apoptotic markers Bcl-2-associated X protein (Bax) and caspase-3 in lung tissue were analyzed using the rat ELISA kit according to the manufacturer's instructions (YL Biont, Shanghai, China). At the end of the analytical process, the color intensity was measured using an ELISA microplate reader (Bio-Tek, Winooski, VT, USA). 
The mRNA transcript levels of tumor necrosis factor a (TNF-a), Interleukin 1 beta (IL -1 $\beta$ ), matrix metalloproteinase-2 (MMP-2), and matrix metallopeptidase-9 (MMP-9), whose primary sequences are listed in Table 1, were analyzed in lung tissue through RT -PCR. For this purpose, total RNA was first isolated from the tissue using QIAzol Lysis Reagent (Qiagen, Cat: 79306, Germany). The concentrations of the total RNAs obtained were measured using the NanoDrop instrument (BIO-TEK INSTRUMENTS EPOCH, USA), and the total RNAs of each sample were counterbalanced accordingly. In the next step, cDNA synthesis was performed from the synchronized total RNAs using the iScript ${ }^{\mathrm{TM}} \mathrm{cDNA}$ Synthesis Kit (BIO-RAD, United States) according to the manufacturer's instructions. mRNA transcript levels were determined on the ROTOR -GENE Q (Qiagen, Germany) instrument using iTaq Universal SYBR Green Supermix (BIORAD) in the final phase. The samples were analyzed in triplicate. b-actin was used as a housekeeping gene. Relative mRNA transcript levels were calculated using CT values from the device and Livak et al.[21]'s ${ }^{-\triangle \Delta C T}$ method.

Table 1. Primer sequences used in the study

\begin{tabular}{|llll|}
\hline Gene & Sequences $\left(\mathbf{5}^{\prime} \mathbf{3}^{\prime}\right.$ ) & Length (bp) & Accession No \\
\hline TNF-a & F: CTCGAGTGACAAGCCCGTAG & 139 & NM_012675.3 \\
& R: ATCTGCTGGTACCACCAGTT & & \\
\hline IL-1b & F: ATGGCAACTGTCCCTGAACT & 197 & NM_031512.2 \\
& R: AGTGACACTGCCTTCCTGAA & & \\
MMP2 & F: CTCTAGGAGAAGGACAAGTG & 158 & NM_031054.2 \\
& R: CTCAAAGTTGTACGTGGTGG & & \\
MMP9 & F: AGCTGGCAGAGGATTACCTG & 230 & NM_031055.2 \\
& R: ATGATGGTGCCACTTGAGGT & & \\
b-Actin & F: CAGCCTTCCTTCTTGGGTATG & 360 & NM_031144.3 \\
& R: AGCTCAGTAACAGTCCGCCT & & \\
\hline
\end{tabular}

\section{Western blot analysis in lung tissue}

The lung tissues were removed and homogenized in RIPA lysis buffer containing protease inhibitör cocktail and PMSF. The samples were centrifuged, and the supernatant was collected. Protein concentration was measured by BCA Protein Assay Kit (Rockford, IL, USA) using bovine serum albumin (BSA) as standard. $30 \mu \mathrm{g}$ of protein from the supernatant was dissolved in Laemmli sample buffer and separated on $10 \%$ sodium dodecyl sulphate polyacrylamide gel (SDS-PAGE). Afterwards, transferred to polyvinylidene fluoride (PVDF) membranes. Blocking was performed by incubating membrane in $5 \%$ BSA for $1.5 \mathrm{~h}$ at room temperature and subsequently were incubated overnight at $4{ }^{\circ} \mathrm{C}$ with primary antibodies against cytochrome c, caspase-3, Bcl-2-associated X protein (Bax), B-cell lymphoma 2 (Bcl-2), beclin-1, 
and $\beta$-actin. After application of the primers, membranes were washed 5 times in PBST for 5 min and left for $1.5 \mathrm{~h}$ in the presence of goat anti-mouse IgG secondary antibody (1:2000 dilution, sc-2005). Protein bands were detected using enhanced chemiluminescence reagent Western ECL Substrate (Bio-Rad, Hercules, USA) and visualized with using ImageQuant LAS 500 (GE Healthcare Bio-Sciences AB, Uppsala, Sweden). Relative density of the bands was quantitied with using Image $\mathrm{J}$ software (NIH, Bethesda, USA).

\section{Statistical Analysis}

Statistical evaluation of the data obtained from biochemical, RT-PCR and western blot analyzes in the study was performed with one-way variance analysis (ANOVA) and Tukey's multiple comparison test in SPSS 20.0 program. Results are presented as mean \pm SD. $P<0.05$ was considered statistically significant.

\section{Results}

\section{Effects of cadmium and carvacrol on oxidant and antioxidant markers in rat lung tissues}

The oxidant (MDA) and antioxidant (SOD, CAT, GPx, and GSH) markers analyzed in lung tissue are listed in Table 2. According to the results, $\mathrm{Cd}$ inhibited the activities of enzymatic antioxidants such as SOD, CAT, and GPx in lung tissue and caused a decrease in GSH stores $(p<0.05)$. In addition, MDA levels, which are an important indicator of lipid peroxidation, were found to increase with $\mathrm{Cd}$ application $(\mathrm{p}<$ 0.05). However, it was observed that the activities of SOD and GPx increased in a dose-dependent manner with the administration of CRV $(p<0.05)$. GPx activity and GSH levels were found to increase with CRV administration, but there was no significant difference between doses. Data obtained include that CRV causes a decrease in MDA levels and that this is dose-dependent $(p<0.05)$. 
Table 2

Effect of Cd and CRV administrations on oxidative stress markers

\begin{tabular}{|c|c|c|c|c|c|}
\hline Parameters & Control & CRV & $\mathrm{Cd}$ & Cd + CRV 25 & $\mathrm{Cd}+\mathrm{CRV} 50$ \\
\hline $\begin{array}{l}\text { MDA (nmol/g } \\
\text { tissue) }\end{array}$ & $\begin{array}{l}34.27 \pm \\
2.18^{a}\end{array}$ & $\begin{array}{l}33.68 \pm \\
1.82^{\mathrm{a}}\end{array}$ & $\begin{array}{l}58.07 \pm \\
2.37^{d}\end{array}$ & $\begin{array}{l}48.14 \pm \\
1.89^{c}\end{array}$ & $\begin{array}{l}41.55 \pm \\
2.09^{\mathrm{b}}\end{array}$ \\
\hline $\begin{array}{l}\mathrm{GSH}(\mathrm{nmol} / \mathrm{g} \\
\text { tissue) }\end{array}$ & $3.65 \pm 0.49^{c}$ & $3.93 \pm 0.26^{c}$ & $2.04 \pm 0.12^{\mathrm{a}}$ & $2.60 \pm 0.15^{\mathrm{b}}$ & $2.94 \pm 0.13^{b}$ \\
\hline SOD (U/g protein) & $\begin{array}{l}27.02 \pm \\
1.22^{\mathrm{d}}\end{array}$ & $\begin{array}{l}27.56 \pm \\
1.46^{\mathrm{d}}\end{array}$ & $\begin{array}{l}15.29 \pm \\
1.17^{\mathrm{a}}\end{array}$ & $\begin{array}{l}18.13 \pm \\
1.04^{\mathrm{b}}\end{array}$ & $\begin{array}{l}22.55 \pm \\
1.26^{c}\end{array}$ \\
\hline GPx (U/g protein) & $\begin{array}{l}17.83 \pm \\
0.93^{c}\end{array}$ & $\begin{array}{l}18.89 \pm \\
0.81^{\mathrm{c}}\end{array}$ & $9.39 \pm 0.86^{a}$ & $\begin{array}{l}13.13 \pm \\
1.02^{\mathrm{b}}\end{array}$ & $\begin{array}{l}14.32 \pm \\
1.37^{b}\end{array}$ \\
\hline $\begin{array}{l}\text { CAT (catal/g } \\
\text { protein) }\end{array}$ & $\begin{array}{l}22.94 \pm \\
1,86^{d}\end{array}$ & $\begin{array}{l}24.60 \pm \\
1.34^{d}\end{array}$ & $\begin{array}{l}12.30 \pm \\
0.95^{\mathrm{a}}\end{array}$ & $\begin{array}{l}15.87 \pm \\
0.79^{b}\end{array}$ & $\begin{array}{l}18.15 \pm \\
0.91^{\mathrm{c}}\end{array}$ \\
\hline
\end{tabular}

\section{Effects of cadmium and carvacrol on inflammatory markers in rat lung tissue}

The effects of $\mathrm{Cd}$ and $\mathrm{CRV}$ on inflammatory markers in rat lung tissue were determined by analysis of p38a MAPK, NF-KB, Bcl-3, iNOS, COX-2, and PGE2 by the ELISA method and TNF- $\alpha$ and IL - $1 \beta$ mRNA transcript levels by the RT -PCR method. ELISA results revealed that $C d$ increased the levels of $p 38 a$ MAPK, NF-KB, Bcl-3, iNOS, COX-2, and PGE2 in lung tissue $(p<0.05)$. However, it was observed that CRV administration decreased p38a MAPK and iNOS levels in a dose-dependent manner $(p<0.05)$. In addition, CRV was found to cause a decrease in NF-KB, Bcl-3, COX - 2, and PGE2 levels, $(p<0.05)$ but there was no statistically significant difference between doses. Figure 1 summarizes the ELISA results. It was found that the mRNA transcript levels of TNF- $a$ and IL $-1 \beta$ increased with Cd application, whereas CRV exerted an anti-inflammatory effect by suppressing these genes $(p<0.05)($ Fig. 2$)$.

\section{Effects of cadmium and carvacrol on apoptotic markers in rat lung tissue}

Apoptotic status in lung tissue was determined by analyzing caspase-3, Bax, Bcl-2, and cytochrome c levels by ELISA and/or Western blot method. The findings showed that $\mathrm{Cd}$ caused a significant increase in caspase-3, Bax, and cytochrome c levels and a decrease in Bcl-2 levels $(p<0.05)$. However, CRV showed anti-apoptotic properties by decreasing caspase-3, Bax, and cytochrome c levels and increasing Bcl-2 levels $(p<0.05)$. On the other hand, ELISA results showed that Bax levels were not significantly different between the Cd + CRV 25 and Cd + CRV 50 groups, but the higher dose was more effective in Western blot analysis $(p<0.05)$. Similarly, it was found that the effect of $50 \mathrm{mg} / \mathrm{kg}$ CRV was higher on $\mathrm{Bcl}-2$ and cytochrome $\mathrm{c}$ levels analyzed by Western blot $(\mathrm{p}<0.05)$. Figure 3 depicts the levels of caspase3 , Bax, Bcl-2, and cytochrome $\mathrm{c}$ in lung tissue. 


\section{Effects of cadmium and carvacrol on 8-OHdG and MPO levels in rat lung tissue}

Based on the results shown in Fig. 4, it was found that the levels of 8-OHdG and MPO were increased in the lung tissue of Cd-treated rats. It was observed that 8-OHdG levels decreased in a dose-dependent manner in rats receiving CRV $(p<0.05)$. It was found that administration of CRV also decreased MPO levels, $(p<0.05)$ but there was no significant difference between doses.

\section{Effects of cadmium and carvacrol on MMP2 and MMP9 mRNA transcript levels in rat lung tissue}

MMP2 and MMP9 mRNA transcript levels analyzed by RT -PCR in lung tissue are shown in Fig. 5 Accordingly, Cd was found to activate MMP2 and MMP9 genes. On the other hand, it was observed that the application of CRV suppressed MMP2 and MMP9 genes $(p<0.05)$.

\section{Discussion}

Because Cd has a half-life of twenty years, even small amounts can accumulate in tissues and cause significant toxic effects [22]. Tissues that suffer from toxic effects include many organs such as the lungs, liver, and kidneys [23]. On the other hand, many beneficial effects are reported for CRV, which has various biological characteristics $[9,10,24]$. The present study investigated the potential protective effect of CRV against Cd-induced pulmonary toxicity in rats.

Several factors are known to play a role in the mechanism of toxicity of Cd in tissues [25]. On the other hand, although $\mathrm{Cd}$ is not a redox-reactive metal, oxidative stress is thought to be the basis of its toxic effects. Cd causes the deterioration of redox homeostasis by removing cations located in the active sites of various antioxidant enzymes. It also binds to the sulfhydryl groups of proteins, including antioxidant enzymes, thereby inhibiting them $[25,26]$. Among them, SOD, CAT, and GPx are well-known antioxidant enzymes $[27,28]$. In addition, Cd causes degradation of cellular GSH, which is an important antioxidant in the body. All this together causes the accumulation of reactive oxygen species and leads to a deterioration of the balance between oxidants and antioxidants [29]. In the present study, CRV was observed to increase the activities of antioxidant enzymes (SOD, CAT, and GPx), possibly by scavenging Cd-derived ROS. In addition, GSH, which has a sulfhydryl group in its structure, was found to increase its levels by protecting it from the effects of $\mathrm{Cd}$. Previous studies have reported that $\mathrm{Cd}$ causes oxidative stress by decreasing the levels of enzymatic and non-enzymatic antioxidants and leading to toxicity in various organs $[1,3]$. On the other hand, different antioxidant compounds used against $\mathrm{Cd}$ have been reported to protect against toxicity by reducing oxidative stress [30,31]. Lipid peroxidation is one of the most critical indicators of oxidative stress, and since MDA is a product of lipid peroxidation, it is an essential indicator for the assessment of the oxidative status [23]. In our study, Cd was observed to cause lipid peroxidation and increase MDA levels in agreement with previous studies [32,33]. However, CRV was observed to protect cell membranes from the effects of $\mathrm{Cd}$ by reducing lipid peroxidation and lowering MDA levels. 
It is known that inflammation, another mechanism for the progression of lung damage, plays an important role, and oxidative stress is one of the triggers of the inflammatory process [34]. Inflammatory cytokines and chemokines are released by lung cells with oxidative stress [35]. NF-KB is one of the main regulatory transcription factors regulating inflammatory responses and coexists with $\mathrm{IKB}$ in the cytoplasm [23]. Bcl-3, localized in the nucleus, is one of the common activators of transcription factors involved in NF-kB signaling [36]. When protein kinases phosphorylate IkB, NF-kB is released and thus enters the nucleus; regulates proinflammatory cytokines such as TNF-a, IL $-1 \beta$, iNOS, and COX - $2[35,37$, 38]. Although PGE-2 plays a vital role in the gastrointestinal tract, it has a proinflammatory effect at high concentrations. p38 MAPK is one of the NF-kB regulators [39]. Cd has been reported to activate the MAPK pathway through the production of ROS [40]. In the present study, Cd was observed to induce p38 MAPK activity and increase Bcl-3 levels depending on ROS production. Thus, it is thought to activate TNF- $\mathrm{a}$ and $\mathrm{IL}-1 \beta$ genes by causing NF-kB activation and increasing iNOS and COX -2 levels. Cd also reduced PGE-2 levels. In previous studies, it has been reported that $\mathrm{Cd}$ triggers the inflammatory process by stimulating pro-inflammatory cytokines $[22,41]$. However, CRV is thought to attenuate Cd-induced oxidative stress through its antioxidant properties, thereby reducing p38 MAPK and NF-kB activation. CRV was also found to reduce levels of Bcl-3, TNF-a, IL $-1 \beta$, iNOS, COX-2, and PGE-2, as well as transcript levels of TNF-a and IL $-1 \beta$.

MPO is a chemokine released by activated neutrophils and macrophages. MPO is known to have potent pro-oxidant and proinflammatory properties [42]. In the present study, an increase in MPO activity was observed in the lung tissue of rats administered $\mathrm{Cd}$. In a previous study, it was reported that Cd caused a significant increase in MPO levels [42]. However, it was observed that MPO activity decreased with the application of CRV.

Measurement of 8-OHdG level is often used to determine DNA damage, a macromolecule that is extremely sensitive to oxidative stress. ROS makes a significant contribution to the formation of 8-OHdG [43]. Cd was reported to increase 8-OHdG levels by causing endogenous oxidative DNA damage in a previous study [26]. In the present study, Cd was found to increase 8-OHdG levels by causing oxidative DNA damage in DNA. However, it was observed that CRV, which alleviates oxidative stress by its ROS scavenging property, reduced Cd-induced 8-OHdG levels in lung tissue.

Increasing evidence points to a close relationship between oxidative stress, inflammation, and apoptosis [41]. In the mechanism associated with oxidative stress, Cd decreases mitochondrial membrane potential by disrupting calcium homeostasis. Thus, it causes the release of cytochrome $\mathrm{c}$ and subsequently caspase-dependent apoptosis [22, 44]. Caspase-3 and Bax are pro-apoptotic proteins, whereas Bcl-2 is anti-apoptotic. Bcl-2 inhibits the release of cytochrome $\mathrm{c}$ by binding to the outer membrane of mitochondria and thus has an anti-apoptotic function. A previous study also reported that NF-kB promotes apoptosis by activating caspase-3 and downregulating Bcl-2 [42]. Proinflammatory cytokines have been shown to contribute to the apoptotic process by activating the caspase family of proteases [45]. A previous study reported that administration of $\mathrm{CdCl} 2$ increased caspase- 3 and Bax levels in cortical tissues and downregulated Bcl-2 levels, triggering the apoptotic process [44]. Cd was observed to 
increase cytochrome c levels, causing caspase-3 activation in the presented study. In addition, Cd was observed to induce apoptosis in lung tissue by causing an increase in Bax levels and a decrease in Bcl-2 levels. On the other hand, it was found that the levels of cytochrome c, caspase-3, and Bax decreased in the lung tissues of rats treated with $\mathrm{CRV}$, whereas Bcl-2 levels increased and protected the lungs from apoptosis.

MMPs are proteolytic enzymes known to play a role in cell migration and tissue remodeling [46]. Among MMPs, MMP2 and MMP9 contribute to tissue remodeling by playing a role in the degradation of collagen and elastase in lung tissue [47]. Recent studies show that ROS, which is derived from NADPH oxidase, can cause MMP activation [48]. It is believed that lung tissue can be protected from inflammation and tissue remodeling by inhibiting MMP activities [46]. A previous study found increased expression of MMP-2 and MMP-9 in arteries of mice exposed to Cd [48]. MMP-2 and MMP-9 have also been shown to be upregulated in patients with acute lung inflammation $[49,50]$. In the present study, a remarkable increase in MMP-2 and MMP-9 mRNA transcript levels was observed in the lung tissue of rats exposed to $\mathrm{Cd}$. However, CRV appears to protect against possible lung tissue remodeling by $\mathrm{Cd}$ by suppressing the expression of MMP2 and MMP9.

\section{Conclusion}

Considering all the results together, it was found that acute $\mathrm{Cd}$ exposure mainly caused oxidative stress in lung tissue and accordingly induced oxidative DNA damage, inflammation, apoptosis, and MMPs. However, it was concluded that CRV could protect the lung by suppressing Cd-induced oxidative stress, inflammation, apoptosis, oxidative DNA damage, and MMPs by exhibiting antioxidant properties.

\section{Declarations}

\section{Fundings}

No funding was received for conducting this study.

\section{Conflicts of interest/Competing interests}

The authors have no conflict of interest.

\section{Availability of data and material}

Not applicable

\section{Code availability}

Not applicable

\section{Authors' contributions}


Kerim Yesildag: Conceptualization, Methodology, Formal analysis, Investigation Cihan Gur: WritingReview \& Editing, Data Curation, Methodology Mustafa lleriturk: Data Curation, Methodology, Conceptualization Fatih Mehmet Kandemir: Data Curation, Methodology, Writing - Original Draft.

\section{Ethics approval}

Ethics committee approval of the study was obtained from Atatürk University Experimental Animals Local Ethics Committee (Approval No. 2018/12/217).

\section{Consent to participate}

Not applicable

\section{Consent for publication}

The author gives her consent for the publication of this manuscript.

\section{References}

1. El-Sokkary GH, Nafady AA, Shabash EH (2010) Melatonin administration ameliorates cadmiuminduced oxidative stress and morphological changes in the liver of rat. Ecotoxicol Environ Saf 73:456-463

2. Demenesku J, Aleksandrov AP, Mirkov I, Ninkov M, Zolotarevski L, Kataranovski D et al (2016) Strain differences of cadmium-induced toxicity in rats: Insight from spleen and lung immune responses. Toxicology letters 256:33-43

3. Ognjanović BI, Marković SD, Đorđević NZ, Trbojević IS, Štajn A, Saičić ZS (2010) Cadmium-induced lipid peroxidation and changes in antioxidant defense system in the rat testes: Protective role of coenzyme Q10 and Vitamin E. Reprod Toxicol 29:191-197

4. Wang Y, Wu Y, Luo K, Liu Y, Zhou M, Yan S et al (2013) The protective effects of selenium on cadmium-induced oxidative stress and apoptosis via mitochondria pathway in mice kidney. Food chemical toxicology 58:61-67

5. Renugadevi J, Prabu SM (2010) Cadmium-induced hepatotoxicity in rats and the protective effect of naringenin. Exp Toxicol Pathol 62:171-181

6. Wu KC, Liu JJ, Klaassen CD (2012) Nrf2 activation prevents cadmium-induced acute liver injury. Toxicol Appl Pharmcol 263:14-20

7. Caglayan C, Kandemir FM, Yildirim S, Kucukler S, Eser G (2019) Rutin protects mercuric chlorideinduced nephrotoxicity via targeting of aquaporin 1 level, oxidative stress, apoptosis and inflammation in rats. J Trace Elem Med Biol 54:69-78

8. Ileriturk M, Benzer F, Aksu EH, Yildirim S, Kandemir FM, Dogan T et al (2021) Chrysin protects against testicular toxicity caused by lead acetate in rats with its antioxidant, anti-inflammatory, and antiapoptotic properties. J Food Biochem 45:e13593 
9. Manouchehrabadi M, Farhadi M, Azizi Z, Torkaman-Boutorabi A (2020) Carvacrol protects against 6hydroxydopamine-induced neurotoxicity in in vivo and in vitro models of Parkinson's disease. Neurotox Res 37:156-170

10. Şen HS, Şen V, Bozkurt M, Türkçü G, Güzel A, Sezgi C et al (2014) Carvacrol and pomegranate extract in treating methotrexate-induced lung oxidative injury in rats. Medical science monitor: international medical journal of experimental clinical research 20:1983

11. Noshy PA, Elhady MA, Khalaf AAA, Kamel MM, Hassanen El (2018) Ameliorative effect of carvacrol against propiconazole-induced neurobehavioral toxicity in rats. Neurotoxicology 67:141-149

12. Bravo D, Pirgozliev V, Rose S (2014) A mixture of carvacrol, cinnamaldehyde, and capsicum oleoresin improves energy utilization and growth performance of broiler chickens fed maize-based diet. J Anim Sci 92:1531-1536

13. Barnwal P, Vafa A, Afzal S, Shahid A, Hasan S, Alpashree et al (2018) Benzo (a) pyrene induces lung toxicity and inflammation in mice: Prevention by carvacrol. Hum Exp Toxicol 37:752-761

14. Kim KS, Lim H-J, Lim JS, Son JY, Lee J, Lee BM et al (2018) Curcumin ameliorates cadmium-induced nephrotoxicity in Sprague-Dawley rats. Food Chem Toxicol 114:34-40

15. Placer ZA, Cushman LL, Johnson BC (1966) Estimation of product of lipid peroxidation (malonyl dialdehyde) in biochemical systems. Anal Biochem 16:359-364

16. Sun Y, Oberley LW, Li Y (1988) A simple method for clinical assay of superoxide dismutase. Clinical chemistry 34:497-500

17. Aebi H (1984) [13] Catalase in vitro. Methods Enzymol 105:121-126

18. Lawrence RA, Burk RF (1976) Glutathione peroxidase activity in selenium-deficient rat liver. Biochem Biophys Res Commun 71:952-958

19. Sedlak J, Lindsay RH (1968) Estimation of total, protein-bound, and nonprotein sulfhydryl groups in tissue with Ellman's reagent. Anal Biochem 25:192-205

20. Lowry OH, Rosebrough NJ, Farr AL, Randall RJ (1951) Protein measurement with the Folin phenol reagent. Journal of biological chemistry 193:265-275

21. Livak KJ, Schmittgen TD. Analysis of relative gene expression data using real-time quantitative PCR and the $2-\Delta \Delta C T$ method. methods. 2001;25:402-8

22. Salama SA, Arab HH, Hassan MH, Maghrabi IA (2019) Cadmium-induced hepatocellular injury: modulatory effects of $\gamma$-glutamyl cysteine on the biomarkers of inflammation, DNA damage, and apoptotic cell death. J Trace Elem Med Biol 52:74-82

23. Yu W, Xu Z, Gao Q, Xu Y, Wang B, Dai Y (2020) Protective role of wogonin against cadmium induced testicular toxicity: Involvement of antioxidant, anti-inflammatory and anti-apoptotic pathways. Life Sci 258:118192

24. Aksu EH, Kandemir FM, Altun S, Küçükler S, Çomaklı S, Ömür AD (2016) Ameliorative effect of carvacrol on cisplatin-Induced reproductive damage in male rats. J Biochem Mol Toxicol 30:513520 
25. Miltonprabu S, Manoharan V (2016) Hepatoprotective effect of grape seed proanthocyanidins on Cadmium-induced hepatic injury in rats: possible involvement of mitochondrial dysfunction, inflammation and apoptosis. Toxicology reports 3:63-77

26. Radwan OK, Alzahrani YA, Kassab RB (2018) Neuroprotective efficiency of Mangifera indica leaves extract on cadmium-induced cortical damage in rats. Metab Brain Dis 33:1121-1130

27. Gur C, Kandemir FM, Darendelioglu E, Caglayan C, Kucukler S, Kandemir O et al. Morin protects against acrylamide-induced neurotoxicity in rats: an investigation into different signal pathways. Environmental Science and Pollution Research. 2021:1-12

28. Celik H, Kucukler S, Ozdemir S, Comakli S, Gur C, Kandemir FM et al (2020) Lycopene protects against central and peripheral neuropathy by inhibiting oxaliplatin-induced ATF-6 pathway, apoptosis, inflammation and oxidative stress in brains and sciatic tissues of rats. Neurotoxicology 80:29-40

29. Refaie MM, El-Hussieny M, Zenhom NM (2018) Protective role of nebivolol in cadmium-induced hepatotoxicity via downregulation of oxidative stress, apoptosis and inflammatory pathways. Environmental toxicology pharmacology 58:212-219

30. Park JH, Lee BM, Kim HS (2021) Potential protective roles of curcumin against cadmium-induced toxicity and oxidative stress. Journal of Toxicology Environmental Health Part B 24:95-118

31. Wang J, Zhu H, Wang K, Yang Z, Liu Z (2020) Protective effect of quercetin on rat testes against cadmium toxicity by alleviating oxidative stress and autophagy. Environ Sci Pollut Res 27:2527825286

32. Gabr SA, Alghadir AH, Ghoniem GA (2019) Biological activities of ginger against cadmium-induced renal toxicity. Saudi Journal of Biological Sciences 26:382-389

33. Chen S, Liu G, Long M, Zou H, Cui H (2018) Alpha lipoic acid attenuates cadmium-induced nephrotoxicity via the mitochondrial apoptotic pathways in rat. J Inorg Biochem 184:19-26

34. Kandemir FM, Caglayan C, Aksu EH, Yildirim S, Kucukler S, Gur C et al (2020) Protective effect of rutin on mercuric chloride-induced reproductive damage in male rats. Andrologia 52:e13524

35. Toygar M, Aydin I, Agilli M, Aydin F, Oztosun M, Gul H et al (2015) The relation between oxidative stress, inflammation, and neopterin in the paraquat-induced lung toxicity. Hum Exp Toxicol 34:198204

36. Caglayan C, Kandemir FM, Darendelioğlu E, Yıldırım S, Kucukler S, Dortbudak MB (2019) Rutin ameliorates mercuric chloride-induced hepatotoxicity in rats via interfering with oxidative stress, inflammation and apoptosis. J Trace Elem Med Biol 56:60-68

37. Yardim A, Kandemir FM, Ozdemir S, Kucukler S, Comakli S, Gur C et al (2020) Quercetin provides protection against the peripheral nerve damage caused by vincristine in rats by suppressing caspase 3, NF-KB, ATF-6 pathways and activating Nrf2, Akt pathways. Neurotoxicology 81:137-146

38. Kandemir FM, Kucukler S, Caglayan C, Gur C, Batil AA, Gülçin I (2017) Therapeutic effects of silymarin and naringin on methotrexate-induced nephrotoxicity in rats: Biochemical evaluation of anti-inflammatory, antiapoptotic, and antiautophagic properties. J Food Biochem 41:e12398 
39. Jiao D, Jiang Q, Liu Y, Ji L (2019) Nephroprotective effect of wogonin against cadmium-induced nephrotoxicity via inhibition of oxidative stress-induced MAPK and NF-kB pathway in Sprague Dawley rats. Hum Exp Toxicol 38:1082-1091

40. Rani A, Kumar A, Lal A, Pant M (2014) Cellular mechanisms of cadmium-induced toxicity: a review. Int J Environ Health Res 24:378-399

41. Aja PM, Izekwe FI, Famurewa AC, Ekpono EU, Nwite FE, Igwenyi IO et al (2020) Hesperidin protects against cadmium-induced pancreatitis by modulating insulin secretion, redox imbalance and iNOS/NF-KB signaling in rats. Life Sci 259:118268

42. Ansari MA, Raish M, Ahmad A, Alkharfy KM, Ahmad SF, Attia SM et al (2017) Sinapic acid ameliorate cadmium-induced nephrotoxicity: In vivo possible involvement of oxidative stress, apoptosis, and inflammation via NF-KB downregulation. Environ Toxicol Pharmacol 51:100-107

43. Kucukler S, Benzer F, Yildirim S, Gur C, Kandemir FM, Bengu AS et al (2021) Protective effects of chrysin against oxidative stress and inflammation induced by lead acetate in rat kidneys: a biochemical and histopathological approach. Biol Trace Elem Res 199:1501-1514

44. Al Olayan EM, Aloufi AS, AlAmri OD, Ola H, Moneim AEA (2020) Protocatechuic acid mitigates cadmium-induced neurotoxicity in rats: Role of oxidative stress, inflammation and apoptosis. Science of the total environment 723:137969

45. Habib R, Wahdan SA, Gad AM, Azab SS (2019) Infliximab abrogates cadmium-induced testicular damage and spermiotoxicity via enhancement of steroidogenesis and suppression of inflammation and apoptosis mediators. Ecotoxicol Environ Saf 182:109398

46. Zhang W, Fievez L, Cheu E, Bureau F, Rong W, Zhang F et al (2010) Anti-inflammatory effects of formoterol and ipratropium bromide against acute cadmium-induced pulmonary inflammation in rats. Eur J Pharmacol 628:171-178

47. Kirschvink N, Vincke G, Fiévez L, Onclinx C, Wirth D, Belleflamme M et al (2005) Repeated cadmium nebulizations induce pulmonary MMP-2 and MMP-9 production and enphysema in rats. Toxicology 211:36-48

48. Sangartit W, Kukongviriyapan U, Donpunha W, Pakdeechote P, Kukongviriyapan V, Surawattanawan $P$ et al (2014) Tetrahydrocurcumin protects against cadmium-induced hypertension, raised arterial stiffness and vascular remodeling in mice. PloS one 9:e114908

49. Fligiel SE, Standiford T, Fligiel HM, Tashkin D, Strieter RM, Warner RL et al (2006) Matrix metalloproteinases and matrix metalloproteinase inhibitors in acute lung injury. Human pathology 37:422-430

50. Ricou B, Nicod L, Lacraz S, Welgus HG, Suter PM, Dayer J-M (1996) Matrix metalloproteinases and TIMP in acute respiratory distress syndrome. Am J Respir Crit Care Med 154:346-352

\section{Figures}


A

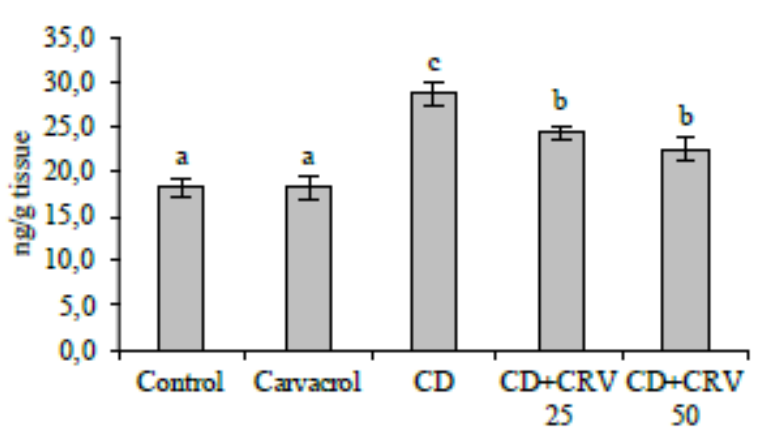

$\mathrm{C}$

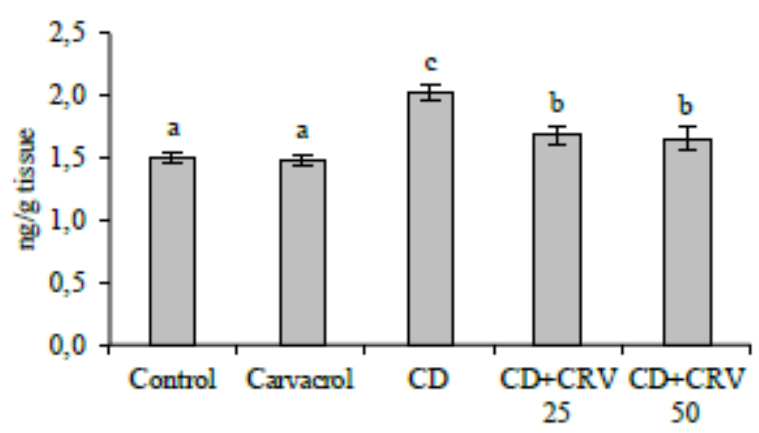

$\mathrm{E}$

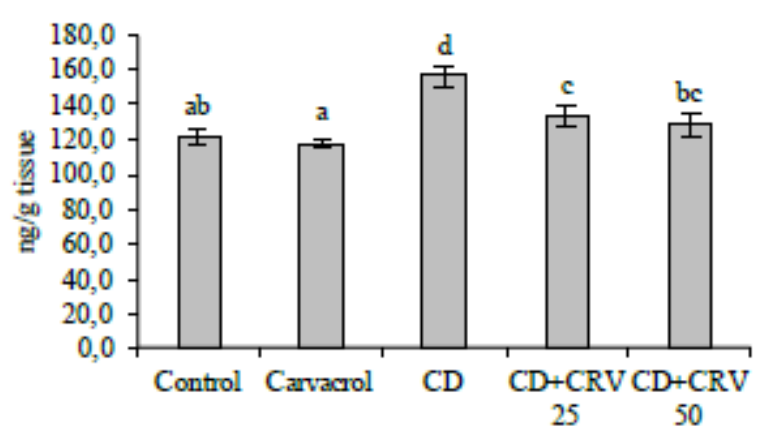

B

MAPK14

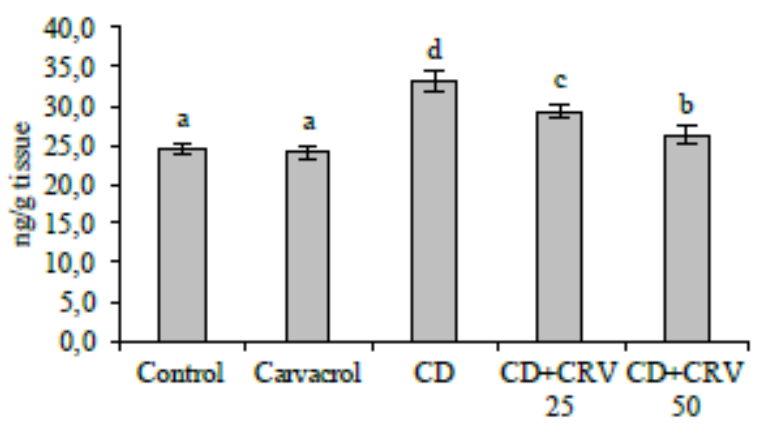

$\mathrm{D}$

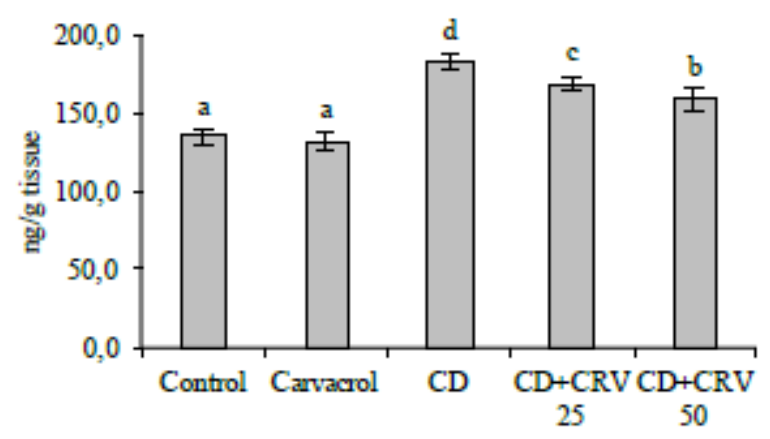

F

PGE2

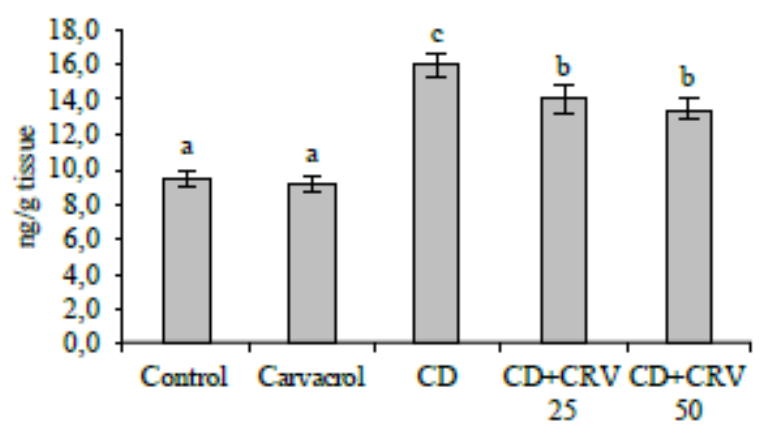

Figure 1

Results of inflammatory markers measured by ELISA method in lung tissues of rats after Cd and CRV administrations. A: NF-KB levels, B: MAPK14 levels, C: Bcl-3 levels, D: iNOS levels, E: COX-2 levels, F: PGE2 levels. Values are expressed as mean $\pm S D$. Different letters $(a-d)$ on the columns show a statistical difference $(p<0.05)$. (Cd; cadmium, CRV; carvacrol, NF-KB; nuclear factor kappa B, MAPK14; mitogenactivated protein kinase 14, Bcl-3; B-cell lymphoma-3, iNOS; inducible nitric oxide synthase, COX-2; cyclooxygenase-2, PGE2; prostaglandin E2) 

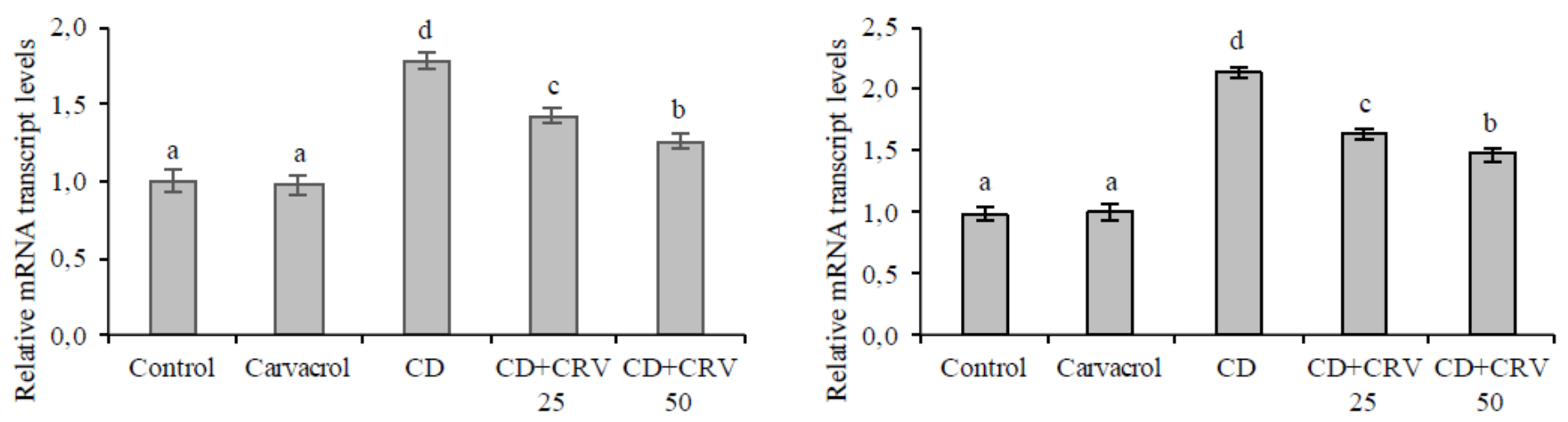

Figure 2

Results of inflammatory markers measured by RT-PCR method in lung tissues of rats after Cd and CRV administrations. A: TNF-a mRNA transcript levels, B: IL-1 $\beta$ mRNA transcript levels, Values are expressed as mean $\pm S D$. Different letters $(a-d)$ on the columns show a statistical difference $(p<0.05)$. (Cd; cadmium, CRV; carvacrol, TNF-a; tumor necrosis factor a, IL -1ß; Interleukin 1 beta)

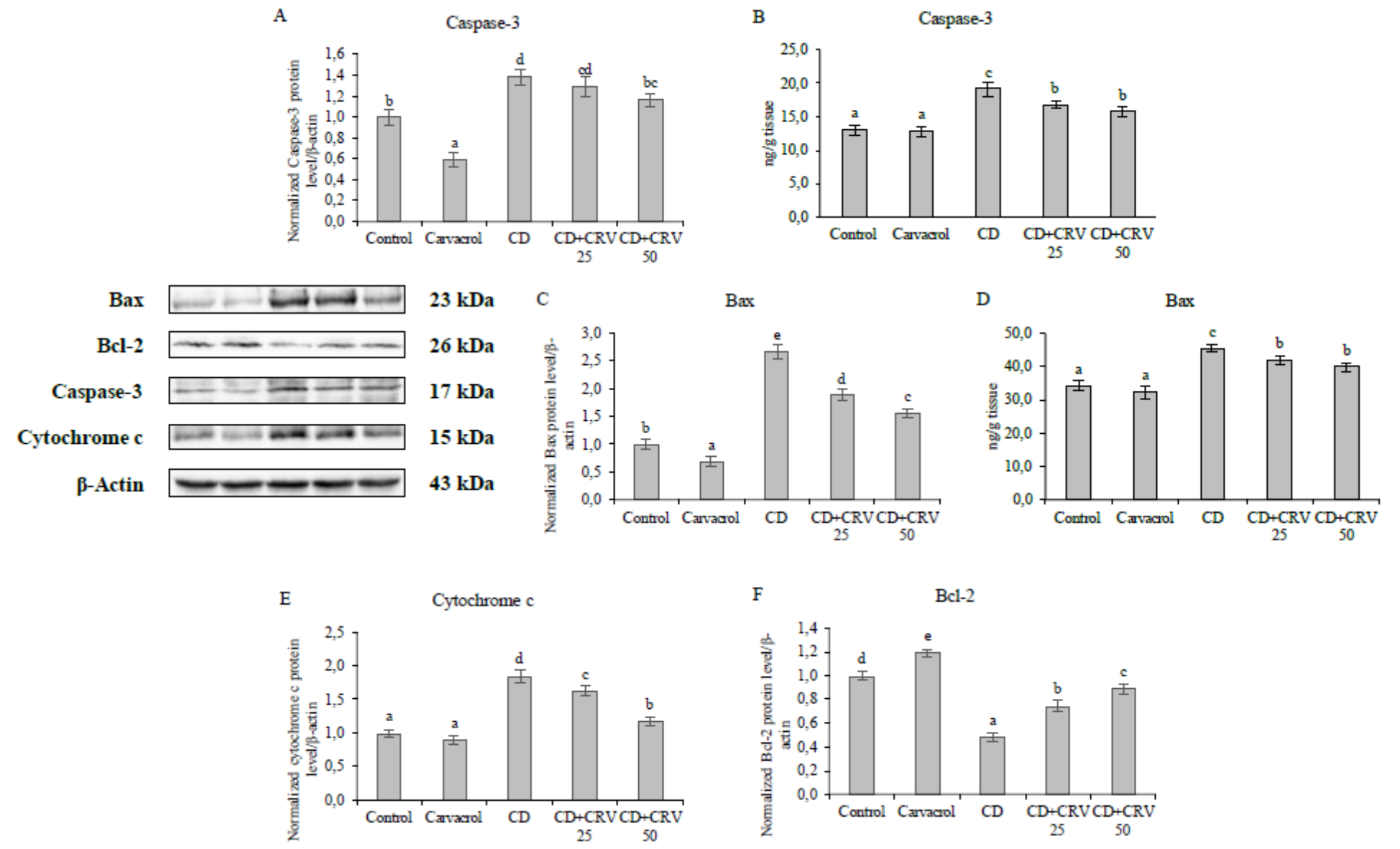

B

Caspase-3

Figure 3 
Results of apoptotic markers measured by ELISA and/or western blot method in lung tissues of rats after $\mathrm{Cd}$ and CRV administrations. A: Normalized Caspase-3 protein level/ $\beta$-actin levels, B: Caspase-3 levels, C: Normalized Bax protein level/ $\beta$-actin levels, D: Bax levels, E: Normalized cytochrome c protein level/ $\beta$ actin levels, F: Normalized Bcl-2 protein level/ $\beta$-actin levels. Values are expressed as mean \pm SD. Different letters $(a-d)$ on the columns show a statistical difference $(p<0.05)$. (Cd; cadmium, CRV; carvacrol, Bax; Bcl-2-associated X protein, Bcl-2; B-cell lymphoma 2)

A

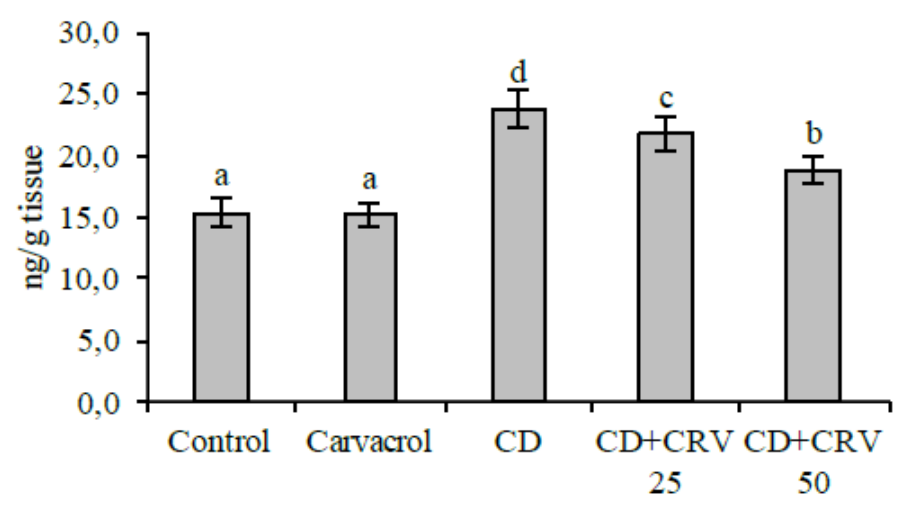

B

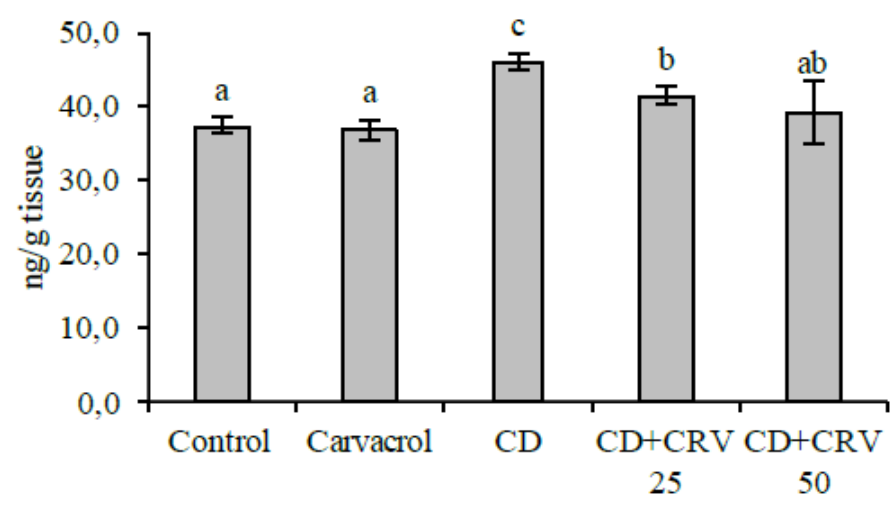

Figure 4

8-OHdG and MPO results measured by ELISA method in lung tissues of rats after Cd and CRV administrations. A: 8-OHdG levels, B: MPO levels. Values are expressed as mean \pm SD. Different letters $(a-d)$ on the columns show a statistical difference $(p<0.05)$. (Cd; cadmium, CRV; carvacrol, 8-OHdG 8hydroxy-2'-deoxyguanosine, MPO; myeloperoxidase)

A

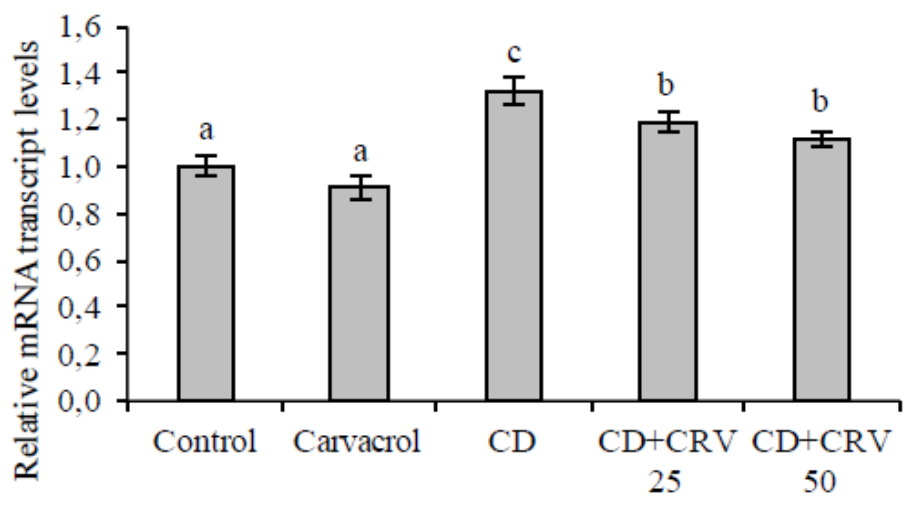

B

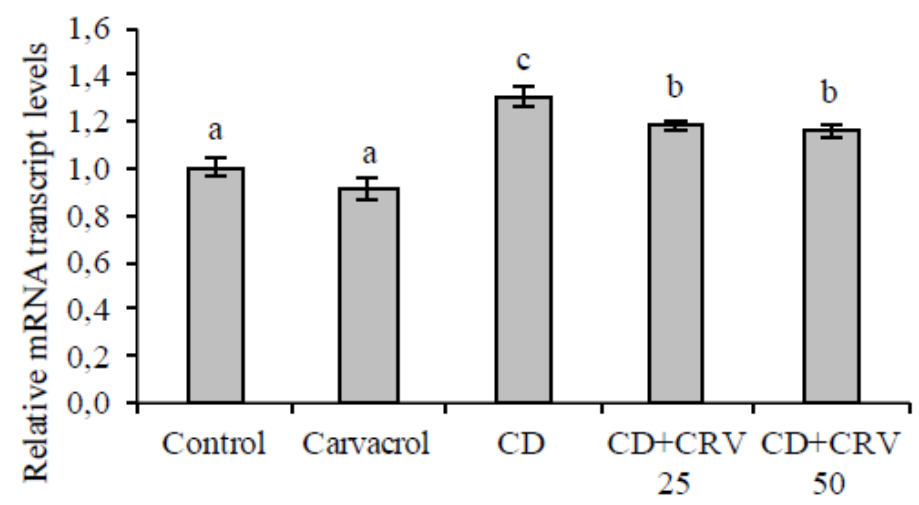

\section{Figure 5}

MMP-2 and MMP-9 mRNA transcript results measured by RT-PCR method in lung tissues of rats after Cd and CRV administrations. A: MMP-2 mRNA transcript levels, B: MMP-9 mRNA transcript levels, Values are expressed as mean \pm SD. Different letters $(a-d)$ on the columns show a statistical difference $(p<0.05)$. (Cd; cadmium, CRV; carvacrol, MMP-2; matrix metalloproteinase-2, MMP-9; matrix metalloproteinase-9) 